\title{
Public Bus Accessibility and its Implications in Energy and Environment: A Case Study of Kathmandu Valley
}

\author{
Anita Prajapati ${ }^{1,}$ *, Tri Ratna Bajracharya ${ }^{1}$, Nawraj Bhattarai ${ }^{1}$, Yngve Karl Froyen ${ }^{2}$ \\ ${ }^{1}$ Tribhuvan University, Institute of Engineering, Pulchowk Campus, Lalitpur, Nepal \\ ${ }^{2}$ Norwegian University of Science and Technology, NTNU, Norway \\ Corresponding Email: anita.praj@pcampus.edu.np
}

\begin{abstract}
:
Growing demand for transport activities has raised numerous transport problems, mainly traffic congestion, environmental and energy issues. Efficient public bus services can be one of the sustainable solutions for meeting local transport demands. But the inefficient operation of public bus services in most of the developing countries has worsened the situation. The multiple service providers, in such open market, compete with each other for their own benefits by adding the number of bus services rather than providing excellent services to users. Accordingly, the number of buses increases that result in higher energy demand and GHG emission. This paper thus aims to analyze the impact of such informal and unregulated transport system prevalent in most of the developing countries focusing mainly on energy and the environment point of views. The study is carried out for the case of Kathmandu valley where the public bus service is owned and operated by multiple service providers. ArcGIS is used to model a public bus network using data available from an open street map. Potential Impact on energy and environment is analyzed using energy modeling tool LEAP. Results show that considerable improvement in energy and emissions can be achieved by improving the public bus services. This paper thus highlights the need for investment in improving access to good public bus services for the sustainable transport planning of the valley.
\end{abstract}

Keywords: Public Transport, Accessibility, Energy

\section{Background}

Unplanned urbanization, increasing motorization, limited transport infrastructure, increasing traffic congestion, and deteriorating air pollution has aggravated the transport system of Kathmandu valley. High urban density and concentrated development have increased traffic volume in the valley tremendously. In addition to that, the rapid growth of private vehicle within the limited transport infrastructure has worsened the peak hour travel as well as brought numerous transport-related challenges like energy security, pollution, accidents, and congestions. The enormous transport energy consumption due to inefficient travel necessitates the effective transport system in the valley. For the country like Nepal, which totally depends on imported fuel, the situation will worsen the economic growth as well as the corresponding impact on the environment [1,2]. Accessible, comfortable, convenient, and safe travel thus is a present need.

Studies have shown that public transport is one of the efficient modes of transportation that transfer lager share of commuters to a long distance with less burden on the economy and environment. It is often considered as sustainable modes of transportation. It can play an essential role in reducing traffic congestion as well as air pollution, provided, it is accessible to all and accommodates the desired level of service. The first prerequisite for public transportation to become a possible alternative for the user is the existence of public transit in a user's neighborhood [3]. Promotion of public transit is thus essential, whereas public transit accessibility is fundamental for an efficient transport service. In most of the developing countries, access to public transport is poor with longer access distance and longer travel time.

Consequently, there is a sizeable increment in private vehicles due to its comfort and ease of reaching destinations. Such increasing transport activities without systematic planning often add problems to the existing situation. The accessible public transport is thus a present need for sustainable transport.

Accessibility is generally the ability to approach facilities, it is also defined as making people travel less by providing facilities within a shorter distance of travel. Accessibility, as explain by Litman, is the overall ability of people to reach services and activities [4]. It is the ease of reaching services/facilities/opportunities [5]. Accessibility has wide range of dimensions, includes, spatial separation(i.e. travel time, travel cost, information, reliability), origins 
(locations, person), destination (job, people, services, facilities), geographical scale (like regional scale), travel modes (public, private), route choice, time of day, environmental impact, and topographic features [5]. Basically, there are two significant aspects of accessibility: physical access to transit lines and geographic coverage reachable within a given travel time budget [6]. Most of the studies on accessibility emphasized the shortest travel time [7-9], travel cost [10], access to stops [6,11], and frequency of service [12]. Short access time and lower travel time increases accessibility, and they often play a crucial role in the choice of the public vehicle against the private vehicle $[6,13,14]$. The understanding of public transport accessibility also gives the insight to transport planners on the area needing investment for planning. A large body of research has been conducted measuring accessibility, but there is limited research on quantifying public transport accessibility in the informal and unscheduled transport system, prevailed in most of the developing countries like Nepal. This research presents the result of a study aimed at identifying the level of public bus accessibility in the Kathmandu valley, considering public bus access and travel time and the consequent impact on environmental and energy.

\section{Characteristics of Kathmandu valley transport system}

Kathmandu, as the capital city of Nepal, is central to any developmental activities. The city is a node for connecting other parts of the country through a designated network. Kathmandu valley constitutes 3 districts including Bhaktapur in East and Lalitpur in the South. The total residential population in the valley is approximately 2.6 million in 2011 [15] and is estimated to be 3 million in 2016 at an annual growth rate of $4.3 \%$ [16]. The high population density in the valley is due mainly to the high rate of immigration as it stands at the center of economic activities that generate $23 \%$ of national GDP [17]. The total area of the valley covers $899 \mathrm{Km}^{2}$.

The public transport system of the valley is generally owned and operated by private companies. There is no fixed bus schedule and is mostly random and uncertain. The demand-oriented transport service provides benefits to the users, but the operation of the routes is concentrated only in the well-established market. There is no guided regulation to access the roads that lead the users inaccessible to public transport where demand is limited. On the other hand, operators compete in running more services in the competitive lines, causing high traffic congestion and service operation inefficient. Competition between operators increases the number of operators in the same market-leading to the complex and incomprehensible network [18]. Numbers of parallel service are in operation adding traffic volume and reducing operators' profitability. This leads to an increase in fare to recover their benefits, and ultimately, users have to pay more than the service they get.

There are approx. 166 city routes (includes bus, minibus, microbus, and tempo routes operating mainly within Ring road and 27 valley bus routes in Kathmandu valley [19]. These vehicles are managed by approximately 100 private operators' association. The public transport network of the valley along with population density is as shown in Figure 1. It shows high population density in the core area supplemented by complex public transport network and sparse in the periphery with the fragile connections. The layout of the system is mostly radial that passes through the city center, and there is one ring road connecting most of the valley routes to the core and peripheral area which covers a significant part of the inner city. Urban households can access bus stop within 12 minutes against national average access time of 30 minutes [20].

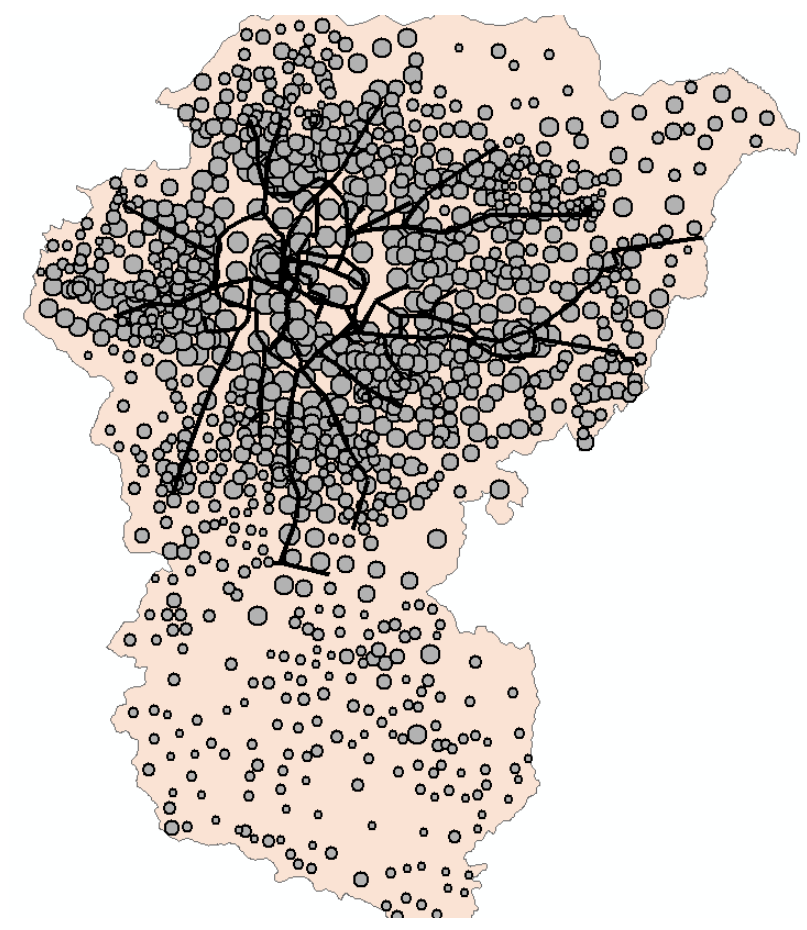

Figure 1: Valley area with transit lines and population density

\subsection{Modes of Public Transport and energy consumption}

Public transport can be categorized into the road-based and rail-based carrier. Rail-based is beneficial in cities 
with high population density. The rail-based are not economically viable in an urban area with a dispersed population [21]. In Nepal, road transport dominates all modes of transportation. Despite the considerable allocation of budget in the transport sector, improvement has not been achieved in the public transport sector. Majority of intracity traffic in Nepal is still contributed by private vehicles. $84 \%$ of the total registered vehicle is motorcycles, but it fulfills only $19 \%$ of total passenger travel demand and consumes $17 \%$ of the gasoline import [23]. At an average annual growth rate of $14 \%$, yearly vehicle registration in the valley has increased dramatically from 40 thousand in 2007 to 120 thousand in 2017. $36 \%$ of the total vehicles registered in Nepal in the roads of Kathmandu valley [24]. The share of different modes of transport is as shown in Figure 2. In 2017, 97\% of registered vehicles were private (motorcycles, car, jeep, van), and only $3 \%$ are public (bus, minibus, microbus, tempo, taxi) in Kathmandu valley [24]. The increasing trend of two-wheelers due to secure access to the congested road and adjustable with limited space and the low capital cost and efficient short distance travel has made it popular in developing countries like Nepal but, indicates the inefficiency of the transport system [25]. Based on registered vehicles, there are only 10 public vehicles per 1000 persons, 47 private vehicles (car/jeep/van) per 1000 persons and 274 motorcycles per 1000 persons in Kathmandu valley in 2017 [15,24]. It shows that the number of public vehicles (buses) that can adequately serve the current travel demand is minimal. This has resulted in high fuel consumption in the transport sector and escalated traffic volume. Compared to increasing global transport energy consumption, attributed mostly to rising household income and number of vehicles [26] consumption in Nepal is very low, but its impact on the national economy is, however, huge due to its total dependence on imported petroleum fuel for all forms of transportation. The introduction of mass public transport that can sustainably meet mobility needs is a present need. Non-Motorized transport is often neglected in most of the developing countries.

According to National Survey of Energy Consumption and Supply Situation in Nepal, energy consumption in the transport sector increases from 640 ktoe in 2011/12 to 836 ktoe in 2015/16, at an annual growth rate of 7\% [23]. According to Economic survey 2017/18, 1.9 million kilolitres of petroleum products were imported in 2016/17 and majority of fuels are consumed in the transport sector, and approximately $60 \%$ of the total imported fuel is consumed by vehicles operating in Kathmandu valley. The current trend of energy consumption in transport will increase the consumption share to $22 \%$ by 2050 from the current 7\% share [27]. Such a tremendous increase in imported fuel use indicates a concern towards energy security and sustainability, dictating the need for energyefficient modes of transport.



Figure 2: Share of transport modes in Bagmati in 2016/17

\section{Past studies on Public Transport}

Studies have been conducted in Kathmandu valley to make public transport efficient and effective. A survey carried out by KSUTP in 2010 conducted a study for public transport and pedestrian network and proposed pilot routes to reduce existing traffic congestion along with detail cost analysis of new buses that are environment-friendly and energy-efficient [19]. The need for large seat capacity bus was felt as a result and numbers of such public bus has been added since then. National Sustainable Transport Strategy (NSTS) for Nepal (2015 2040) was formulated in 2015 with the primary objective to develop sustainable transport policies with the vision of developing a transport system that is efficient, accessible, people-centric, affordable, reliable, safe, inclusive, environmentally friendly, and climate and disaster-resilient [28]. It relates to the degree of accessibility as an economic indicator [28]. It emphasizes the need for good public transport road network without which the addition of private vehicle traffic is inevitable [28]. NSTS sets the target to improve accessibility by minimizing time to the road head and increase the coverage of the network. A master plan for the urban transport improvement for Kathmandu valley was drafted by JICA with the vision of establishing a sustainable urban transport network with high mobility, safety and comfort [29]. It focuses on significant areas like strategic approach, design, sustainability, safety, environment, and culture. Most of the studies raise the issues of public transportation and promotion of mass transportation has been prioritized but the accessibility of public transport, which is a key for the successful operation of public 
transport, is not emphasized by most of the studies. The significant lag in the transport sector of Nepal is not the formulation of policies but its logical implementation.

\section{Methodology}

The public bus network of Kathmandu valley is built and analyzed in ArcGIS. The city base map is taken from the open street map available online. The boundary information is obtained from the Department of Survey, Government of Nepal. Administrative boundary of the valley i.e. disaggregated into 1136 wards served as basic units of analysis where population data are aggregated to its centroid.

Further information added to the network is bus stop locations, the frequency of service, and service operation time. This research is carried out to assess the impact of one of the significant routes, i.e. ring road that surrounds most of the city area and is connected to city routes as well as peripheral routes. The ring road is the circular route covering most of the densely populated valley core area. The total ring length is $27 \mathrm{~km}$.

The accessibility analysis is based on the General Transit Feed Specification (GTFS). GTFS is a standard format based on text files for distribution and exchange of data about transit systems and their schedules. Entirely new GTFS data set is generated for the public transit of Kathmandu valley. It contains the actual street taken by the transit vehicles. The required files to create GTFS dataset are agency.txt, stops.txt, routes.txt, trips.txt, stop_times.txt, and calendar.txt files ${ }^{1}$. New stops, new routes, and new stop patterns can be created in the GTFS database developed for the valley. The general methodology used for developing GTFS route planer is as shown in Figure 3.

GTFS route planner is a tool, developed as part of this research in Microsoft ACCESS for creating transit schedules that can be used for accessibility analysis of the study area. It is a flexible tool that can integrate individual route as per the objective of the study. It also accounts for the uncertainty of service availability that makes it robust and reliable in an unregulated transit system. Also, the model can be easily updated with the availability of more detailed data. It is thus a handy tool for developing a public transport schedule. The trips are generated based on the allocated service time. A sequential link between stops for the transit line is also created. The output data is then imported to an ArcGIS using a tool developed by
$\mathrm{ESRI}^{2}$. ArcGIS is a flexible tool that can interact with other devices. The network analysis is carried out to evaluate the accessibility of bus service. It gives total travel time along with the network, service access time, and geographical coverage within a given travel time budget. The accessibility analysis helps to explore the available transport options to increase the connectivity of the residential areas through less energy-intensive transport modes.

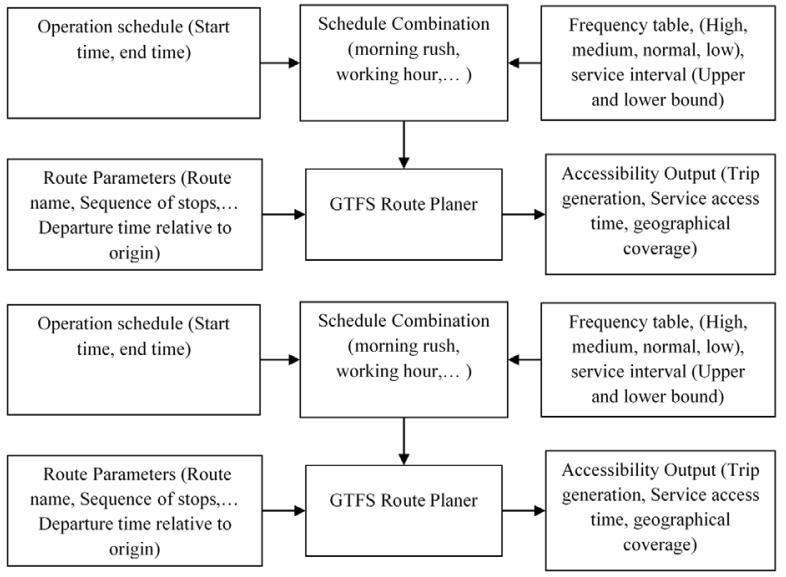

Figure 3: Conceptual framework of the modeling

\section{A case study of Ring Road}

The survey was carried out for the case of the ring road. The operating parameter for the routes number of bus stops, travel time between each stop that includes waiting time and congestion time, number of trips per day, total travel time) required for route planner were collected based on observations and an interview with the drivers during the travel. The service operates for 17 hours from 5:00 AM till 10:00 PM. Most of the services are Non-stop and cover around 5-6 trips per day. There are approximately 42 bus stops along the route. The lack of a well-facilitated bus stop allows the bus to stop in any undesignated locations. Most of the stops are in between 2-3 mins distance in regular traffic and maximum 10-15 mins in a few places because of congestion. The stop count was carried out based on several designated stops (approaching stops, where the driver stops and wait for passenger). There is no fixed starting point in this circular route, the journey starts from different locations of the road. The total travel time along the way varies between 2-3 hrs, depending on the time of day. The field verification of the trip generated by the route planner was done by counting bus/hr at different stops.

\footnotetext{
${ }^{1}$ https://github.com/google/transit/blob/master/gtfs/spec/en/reference.md

${ }^{2}$ https://esri.github.io/public-transit-tools/
} 


\section{$6 \quad$ Findings and Discussions}

The network analysis of the ring road was carried out to measure the total travel time along the route. It shows that the journey can take 103 mins in off-peak-hour to 146 mins in peak hour. Travel time increases in morning rush hour and afternoon rush hour and reduces in other time of day, as shown in Figure 4. It is mainly due to the single shift working model that ends almost at the same time in the evening inducing heavy traffic in the afternoon rush hour. The maximum difference between travel time is approx. 45 mins in peak hour. It thus shows that potential reduction of travel time can be achieved with proper management of traffic in peak hour by shifting traffic volume to an off-peak hour. Introduction of scheduled bus service is an alternative that supply service based on demand reducing the need for private vehicles to fulfill the growing demand. Also, the large-capacity bus transfers a large share of commuters that ultimately reduce traffic volume. Nevertheless, the primary strategy for controlling traffic volume should be reducing the need for private vehicles by increasing the accessibility of public bus that meets the desired service level of users.

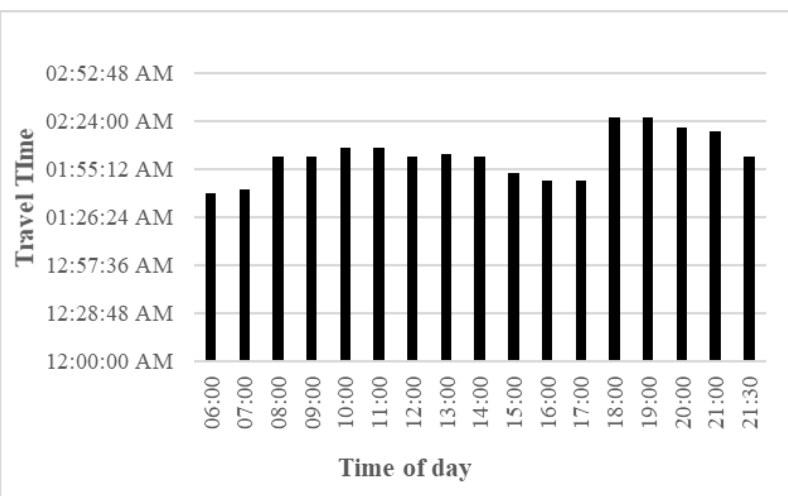

Figure 4: Variation in travel time in a different time of day

Number of trips per hr is the total number of bus service available on the particular bus stop within one hour. It basically gives an idea of the traffic conditions at any stops. The sequential stops, starting from Koteshwor chowk (stop ID: 229) in the counterclockwise direction along with their respective traffic volume, is as shown in Figure 5. It is calculated based on the schedule combinations of the route planner. NumTrips/hr available in each stop is 45 along the ring road when only ring road bus are allowed to operate. But there are numbers of other connecting and parallel routes that pass through ring road. So, when all those routes are also considered, taking vehicle speed as $10 \mathrm{~km} / \mathrm{hr}$, the traffic volume increases considerably. The result shows that NumTrips/hr increases to around 300 in some of the stops (Satdobato, Koteshor, Kalanki and Balkhu) and around 50-100 in most of the stops that have no direct connections to other routes, which is still higher than bus service of ring road, due to the existence of different parallel routes. The averaged NumTrips/hr along the circular route is 160 , which indicates the availability of more than 2 bus per min.

Such a tremendous increase in traffic shows the importance of connecting road in improving accessibility. But on the other hand, it also shows the heavy dependence on a single route to reach most of the desired destinations. It thus dictates the need for alternative ways rather than a widening of the road, to manage growing traffic. The widening of the road in such scenario basically induced more transport in the future, ultimately increasing congestion at an added cost of investment. The rescheduling of the service is essential to make the system more efficient. An integrated service system that provides the facility of transfer can ease the traffic volume substantially.



Figure 5: NumTripsPerHr per stops

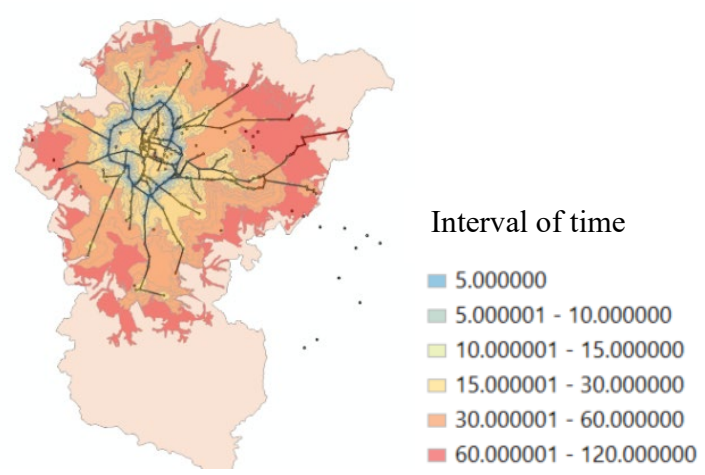

Figure 6: Valley map showing area coverage in the different interval of time

Geographical coverage is another important aspect of accessibility. The coverage from each stop of the ring road under specific travel time budget is measured in the different interval of time: 5, 10, 15, 30, 60, and 120 mins. The coverage within the travel time budget is, as shown in Figure 6. It uses both walking and public transit, which is based on the frequency of service and speed of the vehicle. It demonstrates that most of the core area can be accessed 
within 15-30 mins and, within 60 mins to other peripheral destinations with good public transport. But the marginal area with tenuous connections or no connections at all needs $2 \mathrm{hrs}$ or more to be accessible. Since most of the regions can be reached within an hour from the ring road, the route plays a significant role in mobility. The geographical categorization based on transit service provides input to transport planners in implementing valley transport plans. It can also be a basis for promoting non-motorized transport modes in the valley.

Fuel consumed in a year by the bus of average seat capacity 35 , operating in ring road, is analyzed under different schedule combinations. Two significant cases, one with high frequency, i.e., bus availability per 1-3 mins per stops throughout the day and another with a combination of different frequency in peak and off-peak hour are considered based on high mobility demand of the ring road. To model, the real scenario of the informal transit system, the uncertainty of service availability dominant due to the absence of fixed bus schedule is considered by taking upper and lower bound values of frequency. Results of ring road (only) service shows that total energy consumed in HI_Freq is $70 \mathrm{TJ}$ compared to 43TJ in Combi_Freq scenario. The considerable reduction of $46 \%$ fuel consumption by reducing service availability by 3 mins on average shows that significant saving of imported fuel can be obtained with proper management of traffic. There is a saving of $700 \mathrm{kl}$ of diesel/yr. It shows that the frequency of service can play an essential role in transport energy saving, thus raising a vital issue of scheduled service operation. Based on traffic volume, service can be planned for optimal functioning. Service optimization provides supply based on demand. It thus reduces unnecessary traffic volume reducing fuel consumption even without the need for massive investment. High service availability improves accessibility but demands high energy. Therefore, the optimization of vehicle service is a present need to make transport sustainable. Fuel consumption and trip/day in different scenarios are as shown in Figure 7.

Vehicle emissions (GHGs and SLCPs) from the transport sector is another primary concern that increases with increasing transport activities. The scenario analysis shows that a reduction of $60 \%$ emissions can be obtained with proper schedule combination in peak and off-peak hour. Emissions of different pollutants, calculated based on IPCC guidelines, is as shown in Table 1. The transport sector is one of the significant contributors to air pollution due mainly to enormous traffic volume, unmanaged road, road dust, and construction. The potential reduction can be achieved with improved traffic management and optimal schedule combination.

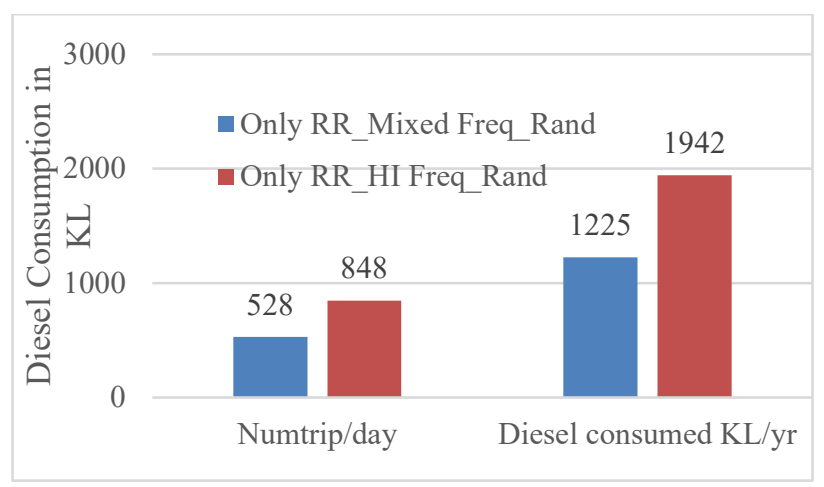

Figure 7: Energy consumption under the different frequency of service availability

Table 1: Emission under the different frequency of service (In metric ton)

\begin{tabular}{|l|l|l|}
\hline Effects & Combi_freq Scenario & HI_Freq Scenario \\
\hline Carbon Dioxide & $3,162.67$ & $5,080.94$ \\
\hline $\begin{array}{l}\text { Carbon } \\
\text { Monoxide }\end{array}$ & 43.16 & 69.34 \\
\hline Methane & 0.22 & 0.35 \\
\hline NMVOCs & 8.63 & 13.87 \\
\hline Nitrogen Oxides & 34.53 & 55.47 \\
\hline Nitrous Oxide & 0.03 & 0.04 \\
\hline Sulfur Dioxide & 7.96 & 12.79 \\
\hline PM2.5 & 16.20 & 26.03 \\
\hline Black Carbon & 38.28 & 61.50 \\
\hline Total & $3,311.68$ & $5,320.33$ \\
\hline
\end{tabular}

\section{Conclusions}

The haphazard bus system of Kathmandu valley has tremendously increased energy consumptions and emissions. The availability of a large number of parallel bus service due to the open market service system has added huge traffic volume along the route. As a result, there is a high frequency of service availability, even in an off-peak hour. Public bus accessibility analysis of one of the primary roads of Kathmandu valley was assessed and analyzed based on travel time and frequency of service along the route. Physical access to the bus stop and geographical coverage in specific travel time budget was analyzed. The geographical categorization provides the basis for the transport planners to plan and implement transport policies. It can also be used to recognize the area with poor accessibility to prioritize investments in transport planning. Based on the frequency of service, 
energy consumption, and consequent emissions were determined. The result of the accessibility analysis shows the need of an integrated transport system for optimal operation of the bus service such that a significant reduction in energy and emission can be achieved without the need for massive investment. Improved accessibility to public transit attracts more users towards it that plays a vital role in assessing the potential energy-efficient transition.

Further research will focus on mapping other public bus routes of the valley and analyzing overall accessibility level including:

- temporarily reliable picture of accessibility by public bus

- localization of zone based on accessibility

\section{References}

[1] H. E. Daly, K. Ramea, A. Chiodi, S. Yeh, M. Gargiulo, and B. Ó. Gallachóir, "Incorporating travel behaviour and travel time into TIMES energy system models," Applied Energy, vol. 135, pp. 429-439, 2014.

[2] H.-D. Waisman, C. Guivarch, and F. Lecocq, "The transportation sector and low-carbon growth pathways: modelling urban, infrastructure, and spatial determinants of mobility," Climate Policy, vol. 13, pp. 106-129, 2013.

[3] D. Teodorović and M. Janić, "Public Transportation Systems," in Public Transportation System Theory, Practice and Modeling, ed, 2017, pp. 387-493.

[4] T. Litman, Evaluating accessibility for transport planning: Victoria Transport Policy Institute, 2017.

[5] A. Hull, C. Silva, and L. Bertolini, "Accessibility Instruments for Planning Practice " 2012.

[6] A. T. Murray and X. Wu, "Accessibility tradeoffs in public transit planning," Journal of Geographical systems, vol. 5, pp. 93-107, 2003.

[7] I. Yatskiv and E. Budilovich, "Evaluating Riga Transport System Accessibility," Procedia Engineering, vol. 178, pp. 480-490, 2017.

[8] E. Yetiskul and M. Senbil, "Public bus transit travel-time variability in Ankara (Turkey)," Transport Policy, vol. 23, pp. 50-59, 2012.

[9] I. Benenson, K. Martens, Y. Rofé, and A. Kwartler, "Public transport versus private car GIS-based estimation of accessibility applied to the Tel Aviv metropolitan area," The Annals of Regional Science, vol. 47, pp. 499-515, 2010.

[10] A. Ford, S. Barr, R. Dawson, and P. James, "Transport Accessibility Analysis Using GIS: Assessing Sustainable Transport in London," ISPRS International Journal of GeoInformation, vol. 4, pp. 124-149, 2015.
[11] T. Saghapour, S. Moridpour, and R. G. Thompson, "Modeling access to public transport in urban areas," Journal of Advanced Transportation, vol. 50, pp. 1785$1801,2016$.

[12] S. Mavoa, K. Witten, T. McCreanor, and D. O’Sullivan, "GIS based destination accessibility via public transit and walking in Auckland, New Zealand," Journal of Transport Geography, vol. 20, pp. 15-22, 2012.

[13] D. Papaioannou and L. M. Martinez, "The Role of Accessibility and Connectivity in Mode Choice. A Structural Equation Modeling Approach," Transportation Research Procedia, vol. 10, pp. 831-839, 2015.

[14] G. Beirão and J. A. Sarsfield Cabral, "Understanding attitudes towards public transport and private car: A qualitative study," Transport Policy, vol. 14, pp. 478-489, 2007.

[15] CBS, "National Population and Housing Census 2011," Central Bureau of Statistics,National Planning Commission Secretatriate, Governement of Nepal, Kathmandu, Nepal2012.

[16] World Bank. (2013). Managing Nepal's Urban Transition. Available:

https://www.worldbank.org/en/news/feature/2013/04/01/m anaging-nepals-urban-transition

[17] NRB, Nepal Rastra Bank, "The Share of Kathmandu Valley in the National Economy," Kathmandu, Nepal2012.

[18] G. Nielsen, J. D. Nelson, C. Mulley, G. Tegnér, G. Lind, and T. Lange, "HiTrans Best practice guide HiTrans Best practice guide 2 Public transport - Planning the networks," 2005.

[19] KSUTP, "Kathmandu Sustainable Urban Transport Project, Final Report," Ministry of Physical Planning and Works, Nepal / Asian Development Bank2010.

[20] CBS, "Nepal Living Standard Survey 2010/11, Statistical Report , Volume One," Central Bureau of Statistics, National Planning Commission Secretariat, Government of Nepal, Kathmandu, Nepal2011.

[21] D. Pojani and D. Stead, "Sustainable Urban Transport in the Developing World: Beyond Megacities," Sustainability, vol. 7, pp. 7784-7805, 2015.

[22] B. Lefèvre, "Urban Transport Energy Consumption: Determinants and Strategies for its Reduction.," Surveys and Perspectives Integrating Environment and Society, vol. 2, 2009.

[23] MOF, "Economic Survey 2015/16," Ministry of Finance, Government of Nepal, Kathmandu, Nepal2016.

[24] DOTM. (2017, July 20, 2017). Department of Transport Management, Ministry of Physical Infrastructure and Transport. Available: https://www.dotm.gov.np/en 
[25] S. Malla, "Assessment of mobility and its impact on energy use and air pollution in Nepal," Energy, vol. 69, pp. 485496, 2014.

[26] H. Ong, T. Mahlia, and H. Masjuki, "A review on energy pattern and policy for transportation sector in Malaysia," Renewable and Sustainable Energy Reviews, vol. 16, pp. 532-542, 2012.

[27] ICIMOD, International Centre for Integrated Mountain Development, "National Action Plan for SLCPs mitigation in Nepal " 2017.

[28] MoPIT, UN-CRD,,, "National Sustainable Transport Strategy (NSTS) for Nepal (2015-2040)," 2015.

[29] JICA, Japan International Cooperation Agency "The Project on Urban Transport Improvement for Kathmandu valley, Volume II, Master Plan and Pilot Project ", Nepal2017. 